\title{
TRADE-OFFS IN ENERGY AND ENVIRONMENTAL POLICY
}

\author{
Maria Teresa Costa-Campi \\ University of Barcelona \& Chair of Energy Sustainability - IEB
}

Pablo del Rio

Institute for Public Policies and Goods (IPP)

Consejo Superior de Investigaciones Científicas (CSIC)

\section{Elisa Trujillo-Baute}

University of Barcelona, University of Warwick \& Chair of Energy Sustainability - IEB

\begin{abstract}
The energy sector is undeniably undergoing a critical period, faced with multiple challenges, whether economic, political or technological. These challenges are related to the requirements set on the sector to meet a wide range of social demands associated with the three traditional dimensions of a sustainable energy system, i.e., environmental sustainability, security of energy supply and economic sustainability. In particular, the environmental pillar has gained ground after the Paris Agreement, which has reinforced the requirement of a low-carbon transformation of the sector. A main challenge is to balance trade-offs among competing goals when designing energy and environmental policies. Although making the energy sector greener is a common aspiration of governments, and many countries are indeed being successful in this regard, the success comes at a price in terms of the other, non-environmental dimensions, of a sustainable energy system. The aim of this special issue is to look in detail on some of the most pressing environmental challenges faced by the energy sector as well as the trade-offs involved in reaching a greener energy system.
\end{abstract}

Key words: trade-offs, energy policy, environmental policy. 


\section{Introduction: trade-offs in energy and environmental policy.}

The energy sector is undisputedly undergoing a critical period, faced with multiple challenges, whether economic, political or technological. These challenges are related to the requirements set on the sector to meet a wide array of social demands which can be linked to the three traditional dimensions of a sustainable energy system, i.e., environmental sustainability (e.g., greenhouse gas mitigation), security of energy supply (diversification of energy sources and reliability of supply) and economic sustainability (a competitive energy system, i.e., affordable energy). The environmental pillar has gained ground after the Paris Agreement negotiated at the $21^{\text {st }}$ Conference of the Parties to the United Framework Convention on Climate Change in December 2015, which declares a global consensus to keep the global mean surface temperature increase below 2 degrees Celsius compared to pre-industrial levels. This Agreement has reinforced the requirement on a low-carbon transformation of the energy sector since it has sent a clear signal to investors, businesses, and policy-makers that the global transition to clean energy is here to stay and resources have to be shifted away from polluting fossil fuels.

However, energy and environmental policy can be expected to result in internal conflicts and contradictions. As in other policy areas, conflicts between objectives are common and an inherent feature of energy policy that needs to be taken into account in regulatory design. This is clearly observed in the European Union (EU), which faces a major challenge in the energy realm: the EU's main energy plan (the Energy Union) needs to be successful in order to comply with the Paris Agreement, but energy policies in Europe also need to be designed in a way which makes the compliance costs affordable for the European economy (Buchan and Keay 2015).

Therefore, a main challenge is to balance trade-offs among competing goals when designing energy policies. As in other policy areas, there is a strong political economy dimension in this debate. Different types of stakeholders put the emphasis on different pillars. Balancing the pressures from different types of stakeholders, in order to make energy and environmental policies more consistent and simpler, is certainly not a trivial issue. Although making the energy sector greener is a common aspiration of governments, and many countries are indeed being successful in this regard, this success comes at a price in terms of the other, non-environmental dimensions, of a sustainable energy system. In particular, rising energy prices and energy costs are a main concern both for consumers and policy makers in Europe and elsewhere, since higher energy prices could 
have detrimental impacts on industrial competitiveness and aggravate the fuel poverty problem suffered by the most vulnerable energy consumers. Indeed, the energy winter package, recently unveiled by the European Commission (see EC 2016), which aims at helping to reduce carbon emissions by $40 \%$ by 2030 , shows both the pre-eminence given to the environmental pillar and the difficulties involved in designing regulation in order to mitigate the conflicts between environmental protection and other policy goals in the energy sector. It is certainly more realistic to consider that energy policy necessarily has to be designed in a context of trade-offs among competing goals.

The aim of this special issue is to look in detail to some of the most pressing environmental challenges faced by the energy sector (without trying to be exhaustive in coverage) as well as the trade-offs involved in reaching a greener energy system. In this context, this special issue covers topics which are deemed relevant on both sides of the Atlantic, and potentially relevant worldwide. These topics include a proposal for a less complex design of climate policies, guidelines on the appropriate design of policies to promote energy storage, smart connections and the market integration of renewable energy, analysis of the consequences of different degrees of harmonization of renewable energy policies in the context of the EU, the impact of electricity losses on $\mathrm{CO}_{2}$ emissions, the efficiency cost of protective measures in climate policy, the drivers for changes of energy costs, the determinants of investment in environmental $R \& D$ and the incentives provided by emissions trading markets to create mergers.

As mentioned above, the focus of this special issue is on the environmental pillar. Our starting point is that environmental challenges and the trade-offs with other competing goals should be contextualised within the energy system, which is made up of several elements as well as the dynamic relationships between them: energy sources and technologies, markets and networks, and public policies (Figure 1). Using an arguably simplified picture of this sector, which nevertheless is deemed useful for illustrative purposes, this sector covers several areas (oil, gas and electricity) and is made up of different energy sources and technologies. Some of these energy technologies can be considered quite mature, whereas others are emerging and are rather immature (storage). Obviously, there are many alternatives in the middle. The position of the technologies along the innovation process, from R\&D to demonstration and deployment suggests that the challenges for these technologies are necessarily different and require different types of public policy support. Note that the technologies themselves interact between each 
other. Often times they compete, but sometimes they complement each other. This is particularly the case of storage and RES, since the former can amplify the diffusion possibilities of intermittent RES. And the other way around: an increasing diffusion of RES encourages the support for the cost reductions and quality improvements in innovation in storage.

Figure 1. Illustrating the interactions between the elements of an energy sector.

ENERGYSOURCS AND TECHNOLOGIES

(innovation, demonstration, diffusion)
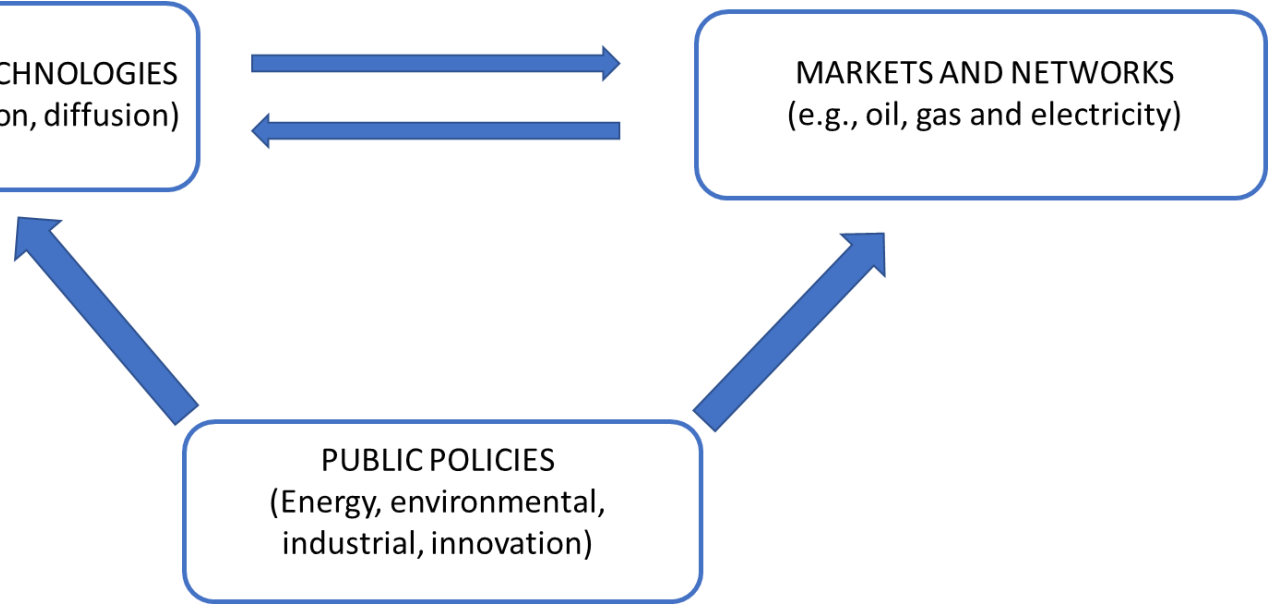

A main techno-economic feature of the recent evolution of the energy sector is the impressive penetration of some technologies in some countries, including the most widespread renewable energy sources (RES) nowadays (wind and solar PV generation) and unconventional gas and oil. These have a critical impact (together with other factors) on a main element of the energy sector, markets and networks, and particularly on the electricity and oil markets. The effect is not univocal, but bidirectional, i.e., the design of existing markets poses challenges for those technologies as well. The deployment of RES affects networks and the electricity distribution model. The deployment of smart grids and distributed generation certainly implies a change in the role of Distribution System Operators (DSOs).

And, obviously, markets, networks and energy technologies can be influenced by policies, which is a third key element in our simplified energy sector framework. Policies can influence directly the other two elements, but also the relationships between them. In short, they can address some of the technological, economic or social acceptability challenges which feature this sector. Relevant policies influencing energy technologies and sources as well as markets and networks are also themselves multifaceted and 
obviously include the most direct influence of instruments and design elements adopted in the energy policy realm, but also industrial, innovation and environmental policies.

This special issue investigates a critical subset of the environmental challenges and associated trade-offs currently faced by the energy sector as affecting the interactions between the aforementioned components of an energy system and derive implications for energy policy accordingly.

In order to advance knowledge regarding some of the most pressing challenges faced by policy makers in tackling the environmental pillar in the energy sector, the associated trade-offs and the implications for the design of energy policies, a Symposium on Energy and Environmental Policy was organised in Barcelona in February 2016, where the papers of this special issue were presented. In this introduction, we have outlined the general framework on the main elements of the energy sector and the potential trade-offs, with a main focus on environmental and energy policy. In the next section, we introduce the articles that make up this special issue.

\section{Overview of the contributions to the special issue}

The papers in this special issue address a subset of the challenges faced by policy makers when designing energy and environmental policies which try to tackle the environmental pillar of a sustainable energy system.

Despite recent achievements towards a global climate agreement, climate action to reduce greenhouse gas emissions remains quite heterogeneous across countries. Tol (this issue) discusses the main policy meta-challenge in the energy and environmental realm: to make policy consistent and simpler in a context of different goals and stakeholders' pressures. His article addresses the political economy of climate policy, which has been subject to the influence of different types of stakeholders, leading to a complex climate policy. The author stresses that first-best climate policy is a uniform carbon tax which gradually rises over time but that civil servants have complicated climate policy to expand bureaucracies, and politicians to create rents. Environmentalists have exaggerated climate change to gain influence, and other activists have joined the climate bandwagon. Opponents to climate policy have attacked the weaknesses in climate research. The climate debate is convoluted and polarized as a result, and climate policy 
complex. Climate policy should become easier and more rational as the Paris Agreement has shifted climate policy back towards national governments. Changing political priorities, austerity, and a maturing bureaucracy should lead to a more constructive climate debate.

A main area in the energy/environmental policy realm is public support for electricity from renewable energy sources. Several papers focus specifically on this area, providing relevant policy implications. An analysis of policy pathways for harmonization of support schemes for electricity from renewable energy sources (RES-E) in a 2030 horizon is carried out by del Río et al (in this issue) according to different assessment criteria with the help of simulations with the Green-X model show. It is found out that there are small differences between the evaluated cases regarding the degree of harmonisation or design elements and that they can mostly be attributed to the different instruments. The model-based assessment clearly points out that the degree of harmonisation has only a small impact upon the performance of an instrument at the aggregated level. In short, compared to other pathways, harmonization (with whatever instrument being chosen) would not be substantially different for the other alternatives. It would modestly increase the static efficiency of RES-E deployment (i.e. cheaper technologies in the best locations), but at slightly higher support costs compared to the alternatives. This suggests that harmonisation would be neither as beneficial as its proponents argue nor as detrimental as its opponents claim.

Another contribution analyses the market compatibility of those support schemes for RES promotion, inferring market compatible designs that make sense (Huntington et al, this issue). The authors argue that, in the past two decades, the growth in RES-E have been largely driven by out-of-market support policies. These schemes were designed to drive deployment on the basis of specific subsidies sustained in time to allow for the larger costs as well as to limit investor risk. While these policies have proven to be effective, the way they have been designed to date has led to costly market distortions that are becoming more difficult to ignore as penetrations reach unprecedented levels. In the context of this growing concern, the authors provide a critical analysis of the design elements of RES-E support schemes, focusing on how they affect this trade-off between promoting and efficiently integrating RES-E. The emphasis is on the structure of the incentive payment, which in the end turns to be the cornerstone for an efficient integration. They conclude that, while needed, a well-designed and further developed 
capacity-based support mechanism complemented with ex-post compensations defined for reference benchmark plants, such as the mechanism currently implemented in Spain, is an alternative with good properties if the major goal is truly market integration. The approach is robust to future developments in technology cost, performance and market penetration of RES-E

In this context, storage and distribution generation (DG) merit a special focus, given their potential contribution to the environmental pillar, but the conflicts, synergies and complementarities with other goals either in the short or longer terms and the role of energy policy design in supporting both is worth analysing.

In the case of storage, Waterson (this issue) shows that storage potentially creates social benefits beyond daily storage in the case of dominance of wind power. These benefits arise from lower requirements for peaking power plant and no need to curtail cheap sources. However, these longer-term benefits cannot be captured commercially by a store operating on the basis of arbitrage, given current technology and forecasting ability. Since longer-term storage does not appear feasible at present, if operated on the basis of price differences, this opens the door for policy support for storage. In the context of wind's high variance and intermittent nature is explored, the authors argue that not only is there a missing money and a missing market issue in providing secure energy supplies, there is also a missing informational issue. A key opportunity for new storage is participation in a capacity market, if the setting is right. Capacity payments could potentially bring social and private incentives more into line, if designed to incorporate storage.

Regarding DG, Anaya and Pollitt (this issue) aim to evaluate and quantify the most relevant benefits from facilitating earlier and greater quantities of DG by examining different connection scenarios using smart solutions. More specifically, the study explores and quantifies the benefits of connecting more distributed generation (DG) with and without the use of smart connections in Great Britain. An analysis of the allocation of these benefits across the different parties—-such as generators, Distribution Network Operators (DNOs) and wider society - is carried out. Alternative connection scenarios are proposed-with partial and full interruptible capacity quotas under a mix of generation with different technology-specific curtailment levels-for integrating DG units in a constrained area of the East of England covered by the Flexible Plug and Play 
project. The smart (interruptible) connection option is the preferred option across all the scenarios. Generators capture most of the benefits while DNOs and wider society capture much less benefit. The smart connection incentive is proposed as an innovative way that allows a fairer allocation of the benefits for connecting more DG. It is found out that there are substantial benefits from smart connection arrangements over conventional alternatives. DG owners benefit the most from smarter connections and the benefits of faster, smarter connection need to be shared out better, in a way that all parties clearly benefit. A main policy-relevant conclusion is that DNOs should be allowed to charge DG owners and that a smart connection incentive should be an option. This would contribute to the reduction of network upgrade or reinforcement costs which usually are borne by customers. Incentives/subsidies paid by wider society are more than their direct benefits, but reflect learning benefits of strategic deployment and cost of achieving the EU renewables target.

Affordable energy is one of the objectives of the EU's energy policy. This goal has been challenged by many factors influencing energy prices and costs such as developments in global energy markets, the EU ETS, and the promotion of renewables. Two contributions address this issue. A main concern of such increase in support costs (which future design of policies should mitigate, as mentioned above) is the threat of competitiveness losses in emission-intensive and trade-exposed (EITE) industries. This is particularly relevant in industrialised countries which face higher cost compared to international rivals due to stringent domestic emission pricing that puts them at a competitive disadvantage against producers of similar goods in other countries with more lenient emission regulation. The cost disadvantage may incentivize relocation of these industries abroad thereby amplifying the adverse impacts for these industries of structural change towards a low-carbon economy. Boehringer et al (this issue) address this important topic, providing critical policy recommendations. This paper focuses on climate policy design in the United States of America (US) and compares the economic implications of four alternative protective measures for US EITE industries: (i) outputbased rebates, (ii) exemptions from emission pricing, (iii) energy intensity standards, and (iv) carbon intensity standards. Using a large-scale computable general equilibrium model, the authors quantify how these protective measures affect competitiveness of US EITE industries. They find that protective measures can improve common trade-related competitiveness indicators such as revealed comparative advantage or relative world 
trade shares but at the same time may lead to a decline in the output value for EITE industries because of negative income effects. The economy-wide cost of emission abatement under protective measures increase as compared to uniform emission pricing stand-alone such that the gains of protective measures for EITE exports may be more than compensated through losses in domestic EITE demand.

On the other hand, Kaltenegger et al. (this issue) assess energy costs in Germany and Europe based on a (Total Real Unit) Energy Cost Accounting Framework. As the authors argue, analysing energy costs (prices times quantity) instead of prices has the advantage of accounting for quantity adjustments. However, it does not allow for monitoring the burden that energy costs pose on firms. For this purpose, both the European Commission and the Energy Expert Commission of the German Government recommend using real unit energy costs, defined as energy costs as a fraction of value added. The authors develop an input-output based (real unit) energy cost accounting framework and study the trends in Germany and the EU between 1995 and 2011. They find that many of the discovered developments are not adequately represented in the political debate, especially with regard to indirect costs (via energy embodied in intermediate inputs), which are more difficult to assess. Indirect energy costs are on the rise, are larger than direct costs in many industries, are increasingly imported, and amplify the asymmetric impacts of legal exceptions available to energy-intensive industries.

In addition to energy policies, other policy realms are as relevant for the required low-carbon transformation. In particular, the development of innovation and environmental policies related to the energy sector will be key to the achievement of environmental objectives.

The impact of policies on innovation aimed at reducing environmental impacts (in short, environmental innovation) represents a crucial element in transition to a cleaner energy sector. One of the contributions (Costa-Campi et al., this issue) analyses the determinants to the investments in environmental innovation, providing critical insights on the public policies which are more effective in triggering those investments. The authors aim to identify the differential determinants of investments in environmental innovation and general innovation. In addition, this paper examines the relationship between environmental innovation $\mathrm{R} \& \mathrm{D}$ expenditure and a range of policy instruments, including environmental regulation and other policy measures including R\&D subsidies 
and environmental taxes. The empirical analysis is carried out for 22 manufacturing sectors in Spain for the period 2008-2013. The findings of this contribution suggest that: 1) Managerial strategy is a relevant driver of environmental $R \& D$ investments. 2) A policy mix of environmental, energy and technological regulatory measures is recommendable. 3) Self-regulation through actions that encourage companies to follow a policy that affects their energy efficiency and is environmentally friendly should be promoted.

Of course, environmental policies have side-effects which might either be desirable or undesirable from a social point of view. One of the papers in this special issue (Creti and Sanin) deals with one of those effects, addressing the impact on mergers. This paper studies merger incentives for polluting Cournot firms under a competitive tradable emission permits market. They find that when firms are symmetric and marginal costs are constant, a horizontal merger is welfare enhancing if efficiency gains are high enough for the merger to take place. The presence of a competitive (or monopolistic) outside market that also trades in the permits market makes profitable a merger that would not happen otherwise. When firms are vertically related in an input-output chain, a horizontal merger in one of the markets increases profits in the other market due to the permits price decrease. Finally, the authors consider an oligopoly-fringe model in which firms differ in their marginal production costs. A merger between the dominant oligopolistic firms decreases the permits price and is always profitable. Such setting is relevant to assess the observed mergers between power generators in several markets for permits, like the Regional Greenhouse Gas Initiative (RGGI), allowing to derive some policy recommendations. More broadly, it suggests that interactions between policies in the energy and environmental policy realm and side effects of public policy interventions need to be considered, addressed comprehensively and, if possible, coordinated.

Finally, it is important to acknowledge the fact that many energy and environmental policies may bring a double social benefit, in terms of energy savings and lower environmental impacts. One of the papers in this special issue clearly shows this. An empirical assessment of the contribution of electricity losses in terms of $\mathrm{CO}_{2}$ emissions is carried out by Daví-Arderius et al (this issue). The authors find that those losses contribute to the system-wide $\mathrm{CO}_{2}$ emissions, and this contribution is different depending on the closing (marginal) technologies. Thus, policies affecting the demand 
and generation sides having an impact on losses will also impact the $\mathrm{CO}_{2}$ content of losses, and through these, the overall system $\mathrm{CO}_{2}$ emissions.

Overall, the special issue illustrates some of the trade-offs which are inherent in policy making in the energy and environmental policy realms. In particular, several articles in this special issue stress the trade-offs between the environmental and economic pillars of a sustainable energy system. Additional policy challenges to be addressed in further research include addressing specific issues, such as how to deal with the environmental impacts of biomass schemes, as well as the more general one of how to make the policy mix consistent, if there should be a policy mix. Although this special issue does not address this latter concern, we believe that the proposed papers provide some of the detailed knowledge that is necessary for the development of a comprehensive energy-environmental policy.

\section{Acknowledgements}

The editors would like to thank all those involved in the "Symposium on Energy and Environmental Policy" held on 2 February, 2016, in Barcelona, Spain. Special thanks are given to the event Keynote Andreas Löschel (University of Münster) and to the ChairDiscussants Paulina Beato (Economic Adviser) and Veronica Lenzi (MEDREG). All the papers in this special issue were sent for a blind peer review process, with at least two referees. The contribution of the referees with their valuable comments and suggestions, improved these special issue papers. Thanks to all of them. We would also like to thank the Energy Policy editors Prof. Michael Jefferson and Prof. Stephen P.A. Brown for their support during the review, production and publication processes. We are also grateful for the generous support of the Chair of Energy Sustainability (Barcelona Institute of Economics, University of Barcelona), the project 2015-SGR-531 of the Generalitat de Catalunya, the project ECO2015-69107-R/MINECO/FEDER, UE funded by the Spanish Ministry of Economics and Competitiveness and the sponsorship by the FUNSEAM. The authors are solely responsible for the views expressed here, as well as all errors and omissions.

\section{References}

Anaya, K., Pollitt, M. (2017). Going Smarter in the Connection of Distributed Generation. Energy Policy 
Boehringer, C., Garcia-Muros, X., Arto, I., Cazcarro, I. (2017). The Efficiency Cost of Protective Measures in Climate Policy. Energy Policy.

Buchan, D. and Malcolm Keay's “Europe's Long Energy Journey: Towards an Energy Union? Oxford Institute of Energy Studies. Oxford University Press for the

Costa-Campi, M.T., García-Quevedo, J.,, Martínez-Ros, E. (2017). What are the determinants of investment in environmental R\&D? Energy Policy.

Creti, A., Eugenia Sanin, M. (2017). Does environmental regulation create merger incentives? Energy Policy.

Daví-Arderius, D., Sanin, M.E., Trujillo-Baute, E. (2017). $\mathrm{CO}_{2}$ content of Electricity Losses. Energy Policy.

Del Río, P., Resch, G., Otner, A., Busch, S., Liebmann, L., Panzer, C. (2017). A technoeconomic analysis of EU renewable electricity policy pathways in 2030. Energy Policy.

European Commission (EC) 2016. Commission proposes new rules for consumer centred clean energy transition. November 30th, 2016. http://ec.europa.eu/energy/en/news/commission-proposes-new-rules-consumer-centredclean-energy-transition

Huntington, S., Rodilla, P., Batlle, C. (2017). Revisiting Support Policies for RES-E Adulthood: Towards Market Compatible Schemes. Energy Policy.

Kaltenegger, M., Löschel, A., Baikowskia, M., Lingensa, J. (2017), Energy Costs in Germany and Europe: An Assessment Based on a (Total Real Unit) Energy Cost Accounting Framework. Energy Policy.

Tol, R. (2017). The structure of the climate debate. Energy Policy

Waterson, M. (2017) The characteristics of electricity storage, renewables and markets. Energy Policy 